\title{
PROJETO DOR ON LINE PERSPECTIVA EDUCOMUNICATIVA E USO DE TECNOLOGIAS DE APRENDIZAGEM
}

\author{
PROJECT DOR ON LINE EDUCOMMUNICATIVE PERSPECTIVES AND LEARNING \\ TECHNOLOGIES USE
}

\section{PROYECTO DOR ON LINE PERSPECTIVA EDUCOMUNICATIVA Y USO DE TECNOLOGÍAS DE APRENDIZAJE}

\author{
Paulo Gustavo Barboni Dantas Nascimento ${ }^{1}$; Mani Indiana Funez ${ }^{2}$; \\ Sabrina Francesca de Souza Lisboa ${ }^{3}$; leda Regina dos Santos ${ }^{4}$; José Waldik Ramon ${ }^{5}$
}

\begin{abstract}
RESUMO
Este trabalho correlaciona a prática educomunicativa e as atividades de confecção de uma edição do periódico Dor on line, uma ação de extensão universitária dedicada à divulgação científica na área do Estudo da Dor, em seu contexto tecnológico e organizacional, com estudantes de graduação e pós-graduação em Saúde e Farmacologia. Este relato traz o uso de tecnologias de aprendizagem em um ambiente virtual de aprendizagem institucional, mimetizando ações editoriais e promovendo a integração dialógica, e diminuindo a distância transacional, estabelecendo fluxos de trabalho operacionais para o desenvolvimento e elaboração de pautas editoriais de jornalismo científico na área da Saúde. A comparação observacional com um sistema editorial dedicado ao projeto e um ambiente de aprendizagem virtual é apresentado, demonstrando a utilidade desta plataforma para os processos educacionais envolvidos no projeto.
\end{abstract}

PALAVRAS-CHAVE: Educomunicação. AVA. Estudo da Dor. Divulgação científica.

\footnotetext{
${ }^{1}$ Doutorado em Química - Universidade de São Paulo (USP). São Paulo, SP - Brasil. Professor adjunto da Faculdade de Ceilândia (FCE/UnB) - Ceilândia do Sul, Brasília, DF - Brasil. E-mail: pbarboni@unb.br

${ }^{2}$ Doutorado em Farmacologia - Faculdade de Medicina de Ribeirão Preto da Universidade de São Paulo (FRMP/USP). Monte Alegre, Ribeirão Preto - SP. Brasil. Professor Adjunto da Faculdade UnB Ceilândia Ceilândia do Sul, Brasília, DF - Brasil. E-mail: mani@unb.br

${ }^{3}$ Doutorado em Ciências - Faculdade de Medicina de Ribeirão Preto da Universidade de São Paulo (FRMP/USP). Monte Alegre, Ribeirão Preto - SP. Pesquisador associado - Faculdade de Medicina de Ribeirão Preto Universidade de São Paulo (FRMP/USP). Monte Alegre, Ribeirão Preto - SP. E-mail:

sabrina.lisboa@gmail.com

${ }^{4}$ Graduação em Biologia - Organização Educacional Barão de Mauá - Centro Universitário Barão de Mauá (CBM) - Ribeirão Preto, SP - Brasil. Especialista em Laboratório (Bióloga) - Universidade de São Paulo (USP). Email: irshivo@fmrp.usp.br

${ }^{5}$ Departamento de Farmacologia - Faculdade de Medicina de Ribeirão Preto - Universidade de São Paulo (USP) São Paulo, SP - Brasil. E-mail: waldik@fmrp.usp.br
}

Submetido em: 16/08/2016 - Aceito em: 12/03/2018

(C) ETD- Educação Temática Digital Campinas, SP $\quad$ v.20 $\quad$ n.2 $\quad$ p. 555-569 abr./jun. 2018




\section{ABSTRACT}

This work correlates the educational practice and the activities of making an issue of the Bulletin Dor on line, a university extension action dedicated to the scientific promotion of the study of pain, in its technological and organizational context, with undergraduate and graduate students in Health and Pharmacology. This report brings the use of learning technologies in an institutional virtual learning environment, mimicking editorial activities and promoting dialogic integration and reducing the transactional distance, establishing operational workflows for scientific journalism in the area of Health. The observational comparison with a dedicated editorial system and a virtual learning environment is presented, demonstrating the usefulness of this platform for the educational processes involved in the project.

KEYWORDS: Educommunication. AVA. Study of Pain. Scientific divulgation.

\section{RESUMEN}

Este trabajo relaciona la práctica educativa y las actividades de hacer una edición del Boletín Dor on line, una acción de extensión universitaria dedicada a la divulgación científica del Estudio del Dolor, en su contexto tecnológico y organizativo, con pregrado y posgrado en Salud y Farmacología. Este informe trae el uso de tecnologías de aprendizaje en un entorno institucional de aprendizaje virtual, imitando las actividades editoriales y promoviendo la integración dialógica y reduciendo la distancia transaccional, estableciendo flujos de trabajo operacionales para el periodismo científico en el área de la Salud. Se presenta la comparación observacional con un sistema editorial dedicado y un entorno de aprendizaje virtual, demostrando la utilidad de esta plataforma para los procesos educativos involucrados en el proyecto.

PALABRAS CLAVE: Educomunicación. EVA. Estudio del Dolor. divulgación científica.

\section{INTRODUÇÃO}

A análise das tendências apresentadas na publicação Horizon Reports 2015 Higher Education (JOHNSON et al., 2015), uma publicação concebida por um consórcio de universidades, faculdades, museus e centros de pesquisa na área de tecnologia na educação, entre outras, mostra uma série de aspectos relacionados à adoção de tecnologias na Educação Superior.

No aspecto relacionado à aceleração da adoção de tecnologias na Educação Superior, temos os seguintes aspectos, a curto, médio e longo prazo:

- $\quad$ aumento do uso de modelos de ensino híbridos;

- $\quad$ a reformulação dos espaços educacionais;

- a proliferação de recursos educacionais de acesso livre;

- $\quad$ aumento do foco na mensuração do aprendizado;

- $\quad$ aumento da colaboração entre Instituições;

- $\quad$ avanço nas Culturas de Troca e Inovação.

$\mathrm{Na}$ análise dos desafios à adoção de tecnologias na Educação Superior, o Horizon Reports 2015 Higher Education identifica como desafios solucionáveis a necessidade de mesclar o aprendizado formal e informal e a de aumentar a fluência digital do público discente. Os desafios difíceis à adoção das tecnologias são identificados como a necessidade do aprendizado individualizado e a do ensino do raciocínio complexo.

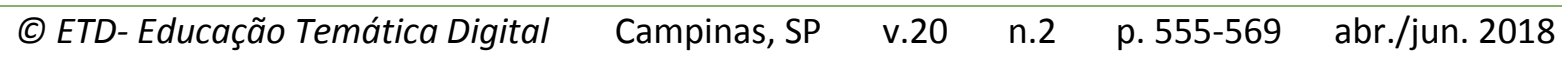


Existem também os desafios muito complexos até mesmo para serem definidos, quiçá resolvidos. Entre eles, está o desenvolvimento de novos modelos educacionais que estão entrando em competição com os modelos vigentes e tradicionais, baseados em horasaula e o ensino instrucional. A educação baseada em competências e o ensino a distância, na forma dos Massive Open Online Courses, estão surgindo como uma alternativa a ser avaliada.

Além disso, outro problema é o papel, em segundo plano, que educar tem na Academia, em relação à Pesquisa. O sobrepeso dado ao pesquisador em detrimento do educador causa um miasma profissional em que é difícil cultivar medidas pedagógicas efetivas e produtivas. Isso subjuga discentes às técnicas ultrapassadas de ensino dos pesquisadores e cujo impacto na qualidade da prestação de serviço à sociedade, no que seria a missão principal da Universidade, a formação profissional, torna-se um complicado item a ser avaliado.

No que diz respeito aos desenvolvimentos tecnológicos importantes para o Ensino Superior, a curto, médio e longo prazo, são discutidos, no Horizon Reports 2015 Higher Education, os seguintes aspectos:

- $\quad$ trazer seu próprio dispositivo, tecnologia, ao ambiente de aprendizagem;

- $\quad$ reorganização do ambiente de aprendizagem, transferindo a propriedade do espaço do professor ao aluno, sobretudo em atividades a distância, das atividades colaborativas e heutagógicas;

- $\quad$ necessidade de desenvolvimento de habilidades e competências na resolução de problemas criativos e de alta complexidade, por meio de design, construção e teste com uso de modelagem virtual, impressão 3D, robótica e eletrônica etc.;

- $\quad$ utilização de novos dispositivos tecnológicos portáteis e usáveis (wearables);

- tecnologias adaptativas para o ensino individualizado; sistemas especialistas;

- Internet das coisas, conexão de objetos, interligando informações por meio da Internet.

O Boletim Dor on line (Dol), enquanto projeto de extensão, em suas práticas educomunicativas durante a produção de conteúdo midiático, utilizando bases tecnológicas para seu funcionamento, atende os desafios mostrados acima?

O objetivo deste relato é explicitar aspectos relacionados ao uso de ferramentas de aprendizagem nos processos de trabalho do projeto, na construção de um ecossistema educomunicativo de Ensino Superior na área da saúde. O intuito é demonstrar que isso viabiliza a divulgação científica e o jornalismo científico responsável, além de contribuir para a formação universitária dos discentes participantes e das perspectivas da adoção de tecnologias na Educação Superior.

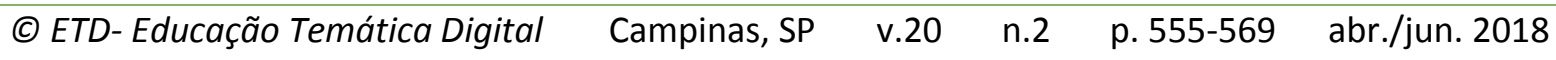




\section{METODOLOGIA}

Neste trabalho, será realizada uma análise comparativa descritiva entre os métodos e fluxos de trabalhos de dois recursos editoriais utilizados no Projeto Boletim Dor on line. Os recursos de comunicação e aprendizagem serão descritos e comparados, com ênfase nos processos educacionais relacionados e em atendimento aos destaques mostrados para a aplicação de novas tecnologias no Ensino Superior.

\section{A EXPERIÊNCIA REALIZADA}

\subsection{Resultados no Uso de Tecnologias de Aprendizagem}

O projeto de extensão de ação continuada, implementado na Faculdade de Ceilândia da Universidade de Brasília, conta com um meio ambiente educacional que propicia a adoção tecnológica. Esta IES tem, em sua estrutura, a Diretoria de Ensino de Graduação a Distância, encarregada do suporte tecnológico dos projetos dos Institutos e Faculdades para a oferta regular dos cursos de graduação a distância e integração das ofertas nas unidades acadêmicas. Ela disponibiliza a Plataforma Aprender, um Ambiente Virtual de Aprendizagem (AVA), que apoia professores e alunos em atividades de ensino, disponibilizando conteúdos e ferramentas de aprendizado de um curso ou disciplina, possibilitando uma maior interação entre alunos, professores e monitores envolvidos no processo de ensinoaprendizagem, rompendo limites presenciais e favorecendo a formação dos estudantes ("Aprender.unb.br", 2015). A Plataforma Aprender iniciou o primeiro semestre de 2015 com cerca de 2 mil cursos/disciplinas e registro de mais de 33 mil contas de usuários cadastrados.

Com isso, esta IES atende o uso de modelos de ensino híbridos, com reformulação dos espaços educacionais, utilizando a plataforma Moodle, como AVA, um recurso educacional de acesso livre.

Nesse ambiente, a atividade de comunicação, segundo a proposta de divulgação científica na área da Saúde, no Estudo da Dor, exige dos envolvidos, em sua elaboração, o uso e refino de habilidades e competências transdisciplinares, demandando muitas vezes o aprendizado heutagógico (Hase \& Kenyon, 2000), aliado a práticas educomunicativas, de maneira a lograr a produção de artigos de jornalismo científico de qualidade (Bueno, 2010), atingindo êxito na ação extensionista proposta pelo projeto.

(C) ETD- Educação Temática Digital Campinas, SP $\quad$ v.20 $\quad$ n.2 $\quad$ p. 555-569 abr./jun. 2018


O AVA aqui discutido possibilita a integração de atividades desenvolvidas no âmbito do projeto e a integração institucional entre o grupo de trabalho da UnB e o grupo de trabalho da Faculdade de Medicina de Ribeirão preto, Universidade de São Paulo, promovendo um fluxo de trabalho para a produção mensal da edição do Boletim Dor Onsine.

A interação em ambientes virtuais é muito importante para o processo de significação de participantes de atividades instrucionais a distância, pois possibilita a promoção do aprendizado significativo, construído predominantemente de maneira heutagógica, mas que se utiliza da socialização e comunicação colaborativa para a consolidação e obtenção de perspectiva crítica desse conhecimento (Moore, 1997).

As ferramentas escolhidas para exemplificar a interação nos ambientes virtuais e a promoção da aprendizagem na educação a distância foram dois fóruns, em plataformas diferentes, no contexto do Projeto Dor on line, edição mensal eletrônica e portal sobre estudo da Dor e que tem a finalidade de divulgar informações sobre o tema Dor, de maneira a incentivar o interesse e facilitar o entendimento de notícias e artigos mais atuais sobre o assunto, como mostrado na Tabela 1. O produto, a edição mensal, visa como público-alvo a três segmentos: 1) estudantes e pesquisadores, 2) clínicos e especialistas e 3) público em geral, procurando utilizar uma linguagem acessível aos diferentes tipos de leitores. Um exemplo do produto pode ser visualizado no Diagrama 1.

TABELA 1: Comparação entre os Ambientes Editoriais utilizados no Projeto de Extensão

Recurso 1

Recurso 2

http://www.dol.inf.br/asp/discussao/Nsforum.asp

Fórum em sistema dedicado. Área de acesso privada. Detalhes nas figuras 1, 2, 3.

Boletim elaborado pela disciplina de "Revisão e discussão da literatura experimental e clínica atual sobre Dor e Analgesia I e II" da Pós-Graduação em Farmacologia da FMRP-USP.

Participam alunos de pós-graduação stricto sensu em farmacologia da Dor e Inflamação, e pósdoutorandos do Laboratório de Dor e Inflamação. http://www.ead.unb.br/aprender2013/mod/foru $\underline{\mathrm{m} / \text { view.php?id }=1880}$

Fórum no AVA MOODLE 2.4 da UnB. Acesso a visitantes permitido. Detalhes na Figura 4.

O Boletim DOL também faz parte do projeto de extensão de ação contínua em Comunicação da Universidade de Brasília, Decanato de Extensão campus Ceilândia (Faculdade de Ceilândia, FCE). 


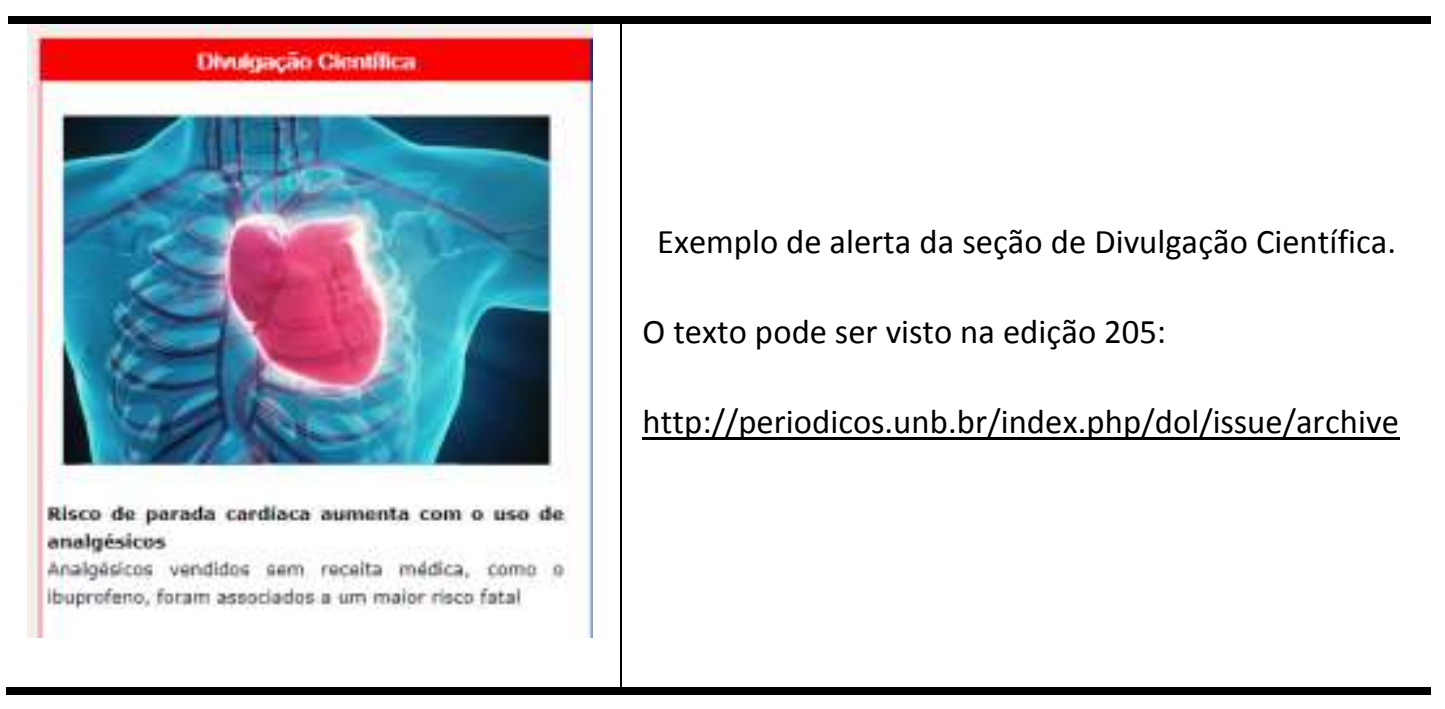

DIAGRAMA 1: Produto de reportagem científica do Projeto.

O projeto constitui uma ação de educomunicação, conforme definida por Soares (Soares, 2014), em um âmbito sociointeracionista, promovendo dialogia, participação e protagonismo dos participantes do projeto, dentro de um ecossistema comunicativo, com participação horizontal, apropriação disseminada de mídia e linguagem própria ao estudo da Dor, explorando a experiência dialógica como construtora de consciência crítica disseminada então à sociedade por meio de recursos tecnológicos de Comunicação.

Soma-se a esse objetivo a promoção da capacitação de alunos de graduação e pósgraduação em jornalismo científico e desenvolvimento crítico acerca dos assuntos tratados, além da produção colaborativa dos textos desenvolvidos no âmbito do projeto.

Este projeto tem seu desenvolvimento em duas Instituições de Ensino Superior (IES), em duas unidades federativas diferentes, o estado de São Paulo e o Distrito Federal.

No Distrito Federal, o projeto é uma ação de extensão universitária na área de Comunicação, contando principalmente com alunos de graduação de cursos em Saúde, em que se aplica o desenvolvimento do raciocínio crítico. Os cursos de graduação na área da Saúde do campus Ceilândia da UnB foram idealizados e elaborados em "consonância com as Diretrizes Curriculares Nacionais pra a área da Saúde, que se propõem formar profissionais em uma perspectiva generalista, humanista, crítica e reflexiva, e capacitados a atuar em todos os níveis da atenção à Saúde" (Farmácia (FCE/UNB), 2010). Além disso, os princípios orientadores do Projeto Pedagógico dos Cursos assumem os seguintes princípios: o Campo da Saúde, a Concepção de Saúde, a Saúde-Doença como um processo, a interdisciplinaridade e a integralidade da atenção à Saúde.

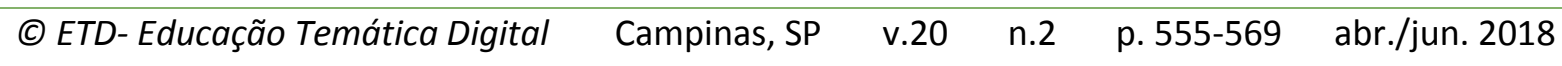


O projeto Dor on line possibilita um processo de aprendizado que utiliza os princípios norteadores dos cursos de graduação em Saúde da FCE e promove aprendizado significativo e explicitação de conhecimento tácito de seus participantes no conhecimento e na avaliação do conhecimento envolvido no estudo da Dor, formando um ecossistema comunicativo.

TABELA 2: Comparação entre as Potencialidades Pedagógicas utilizadas no Projeto de Extensão.

\begin{tabular}{|c|c|}
\hline Recurso 1 & Recurso 2 \\
\hline $\begin{array}{l}\text { Construído de maneira colaborativa pelo } \\
\text { webdesign do projeto, utilizando o sítio } \\
\text { www.dol.inf.br. }\end{array}$ & $\begin{array}{l}\text { Fórum em uma disciplina no AVA, dedicado à } \\
\text { atividade editorial de um boletim mensal sobre } \\
\text { estudo da Dor e repositório de produtos de } \\
\text { comunicação digital na área do estudo da Dor. } \\
\text { AVA estabelecido dentro da Diretoria de Ensino de } \\
\text { Graduação a Distância, que é responsável por } \\
\text { orientar, coordenar, dar suporte tecnológico e } \\
\text { assessorar os projetos dos Institutos e Faculdades } \\
\text { da Universidade de Brasília - UnB -, para a oferta } \\
\text { regular dos cursos de graduação a distância e } \\
\text { integração das ofertas nas unidades acadêmicas. }\end{array}$ \\
\hline $\begin{array}{l}\text { http://aprender.ead.unb.br/mod/resource/view.p } \\
\text { hp?id=92058 }\end{array}$ & $\begin{array}{l}\text { Participação contextualizada a partir de interação } \\
\text { reativa, com os alertas elaborados pelo aluno pela } \\
\text { submissão de um potencial alerta ou editorial. }\end{array}$ \\
\hline $\begin{array}{l}\text { Permite transparência de processo elaborativo e } \\
\text { coordenação de atividades a serem realizadas } \\
\text { pelos membros da ação. }\end{array}$ & $\begin{array}{l}\text { Projeto de extensão de ação contínua: tem como } \\
\text { objetivos o desenvolvimento de comunidades, a } \\
\text { integração social e a integração com instituições } \\
\text { de ensino. São projetos desenvolvidos ao longo do } \\
\text { ano letivo, podendo ser renovados no ano } \\
\text { seguinte, mediante solicitação encaminhada à } \\
\text { Câmara de Extensão (CEX). } \\
\text { Elaboração de comunicação escrita e sugestões } \\
\text { decorrentes das reuniões de pauta e demais } \\
\text { situações. } \\
\text { Treinamento instrucional em crítica científica e } \\
\text { jornalismo científico na área do estudo da Dor. }\end{array}$ \\
\hline $\begin{array}{l}\text { Treinamento instrucional em crítica científica e } \\
\text { jornalismo científico na área do estudo da Dor. }\end{array}$ & $\begin{array}{l}\text { Treinamento em apresentação e discussão de } \\
\text { artigos científicos da área de estudo da Dor. }\end{array}$ \\
\hline $\begin{array}{l}\text { Constitui uma ação de educomunicação, envolvida } \\
\text { na produção de media para educação em estudo } \\
\text { da Dor. }\end{array}$ & $\begin{array}{l}\text { Estimulação da significação de conteúdos } \\
\text { instrucionais dos cursos de graduação em Saúde } \\
\text { cursados pelos extensionistas; e sua } \\
\text { operacionalização pela produção dos alertas e } \\
\text { editoriais, atividades com produto final definido e } \\
\text { na área da Comunicação. }\end{array}$ \\
\hline
\end{tabular}

(C) ETD- Educação Temática Digital Campinas, SP $\quad$ v.20 $\quad$ n.2 $\quad$ p. 555-569 abr./jun. 2018


Os responsáveis pela elaboração utilizam como referência uma publicação mensal específica na área do estudo da Dor, classificada como $\mathrm{A} 1$ pelo QUALIS CAPES em todas as áreas disponíveis. A publicação apresenta um perfil multidisciplinar em seus artigos e propicia discussões de diferentes campos do conhecimento da área da Saúde.

O projeto conta com uma reunião presencial semanal, em cada uma das IES, para elaboração da pauta da edição mensal, disponibilizada em www.dol.inf.br e http://periodicos.unb.br/index.php/dol/index, em formato de livro digital. Nessas reuniões são definidos os componentes de cada edição e são realizadas discussões presenciais, a partir do material pesquisado oriundo desse fluxo de trabalho, sobre os temas levantados. A proposta do livro digital, em formato .EPUB, atende o aspecto levantado de utilização de novos dispositivos tecnológicos portáteis e usáveis (wearables) e alguns exemplos encontram-se no Diagrama 2.

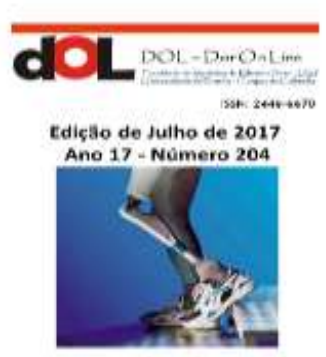

\section{n. 204 (17): Dol}

edição 204

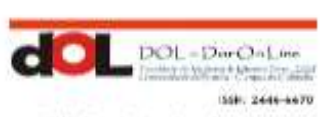

\section{n. 203 (17): Dol}

Ediçãp 203

Ediçăo de Junho de 2017
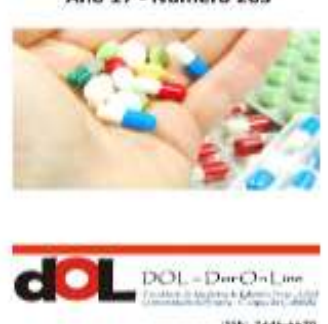

\section{n. 202 (17): Dol}

Ediç3o de Maio de 2017 edição 202

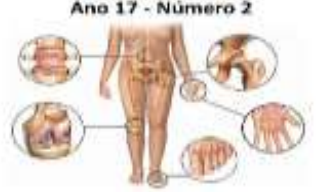

\author{
Exemplo, livros digitais \\ Disponível em : \\ http://periodicos.unb.br/index.php/dol/issue/archive
}

DIAGRAMA 2: Produtos tecnológicos do Projeto, acessíveis para dispositivos digitais portáteis.
(C) ETD- Educação Temática Digital
Campinas, SP
v.20
n.2
p. 555-569 abr./jun. 2018 
Este projeto utiliza os fóruns para a promoção da interação e integração dos conteúdos produzidos, por meio de espaços virtuais que promovam a elaboração colaborativa e a síntese crítica dos aspectos abordados nas interações dialógicas das reuniões de pauta e no fórum do AVA da UnB.

Os dois fóruns têm diferenças importantes (Tabela 2), pois o fórum em sistema dedicado do Dol tem predominância de interações reativas com o ambiente, já que o interesse principal é o processo dialógico presencial desenvolvido nas reuniões de pauta. Ele utiliza imagens para codificar as etapas de editoração e possibilita o fluxo de trabalho colaborativo de media, distribuída como conteúdo da edição mensal do Boletim (Diagrama 3).

Já o fórum no AVA da UnB tem uma relevância maior para a interação mútua dos alunos de graduação, que são estimulados a participarem da elaboração dos produtos textuais elaborados pelos extensionistas do projeto. Esse direcionamento proposital tem origem nas diferenças de fluxo de trabalho entre as duas IES, pois na UnB temos principalmente alunos de graduação participando do projeto, enquanto que, na USP, a composição do corpo editorial tem predominância de mestrandos, doutorandos e pósdoutorandos em Farmacologia, com diferentes graduações (Tabela 3).

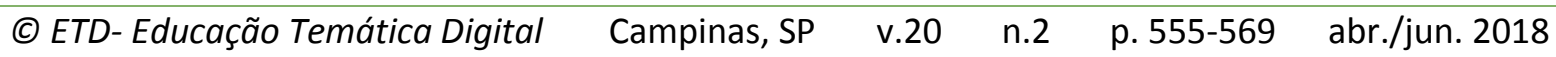




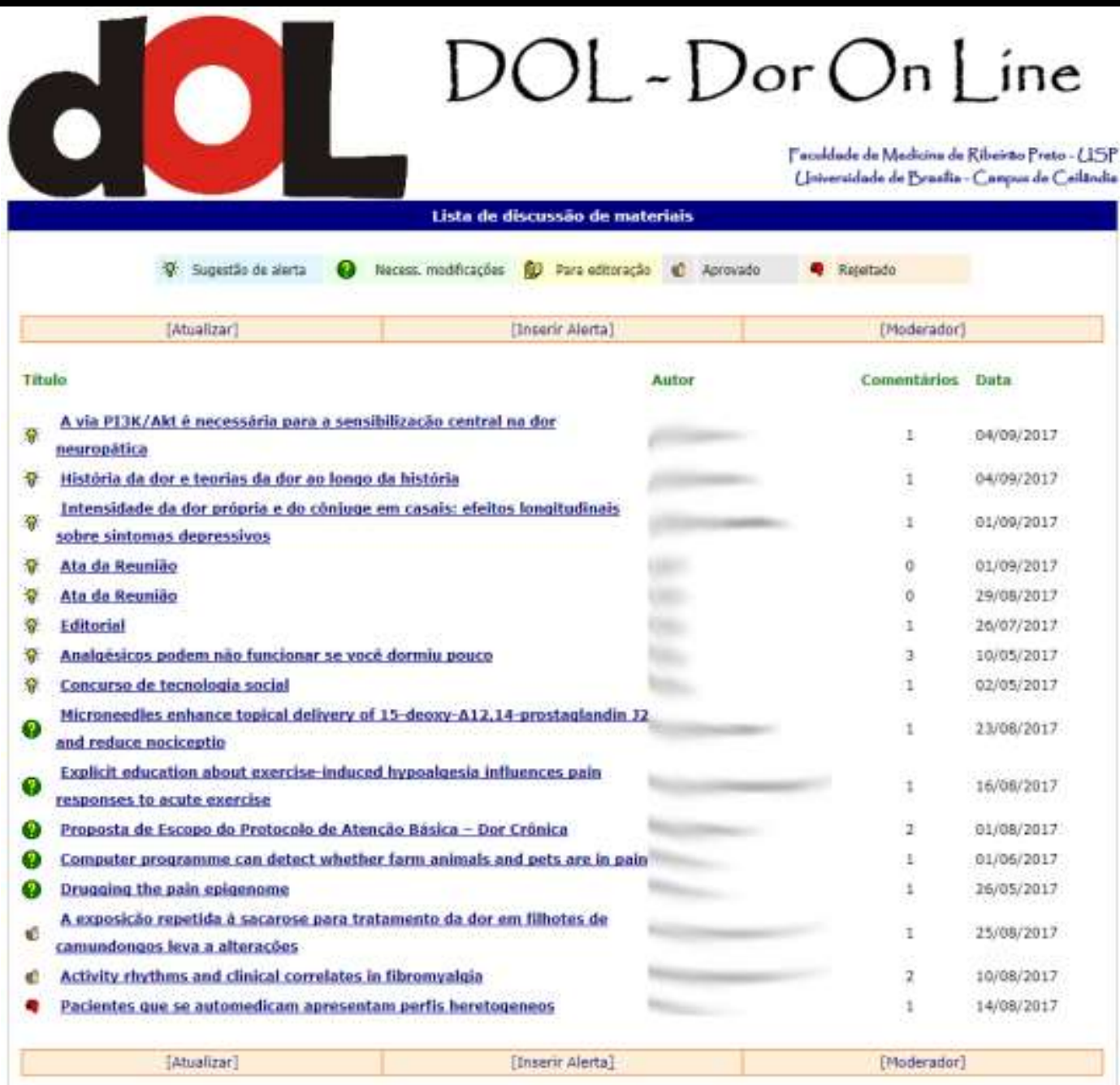

DIAGRAMA 3: Exemplo do Ambiente Virtual de Editoria do Dor on line.

Evidenciam-se as diferenças entre os dois tipos de tecnologia e usos, em contextos diferentes, nas Tabelas apresentadas. Nelas, são comparadas as potencialidades pedagógicas de cada um dos fóruns, os limitadores de cada ambiente, é descrito como se dá a participação dos alunos e as possibilidades de interação e interatividade.
(C) ETD-Educação Temática Digital
Campinas, SP
v.20
n.2
p. 555-569 abr./jun. 2018 
TABELA 3: Comparação entre Limitadores de Ambiente utilizados no Projeto de Extensão.

\begin{tabular}{|c|c|}
\hline Recurso 1 & Recurso 2 \\
\hline $\begin{array}{l}\text { A finalidade do fórum é a de apresentar e integrar } \\
\text { o material a ser avaliado, trazido pelo corpo } \\
\text { editorial do } D O L \text { e pelos participantes das } \\
\text { disciplinas de pós-graduação em farmacologia da } \\
\text { FMRP. }\end{array}$ & $\begin{array}{l}\text { A finalidade do fórum é a de apresentar e integrar } \\
\text { o material a ser avaliado, trazido pelo corpo } \\
\text { editorial do } D O L \text { e do projeto de ação contínua de } \\
\text { extensão universitária Boletim Dor on line, na área } \\
\text { de Comunicação. }\end{array}$ \\
\hline $\begin{array}{l}\text { Um limite bem definido é estabelecido para a } \\
\text { utilização do fórum, sendo utilizada como subsídio } \\
\text { a reunião semanal de pauta, uma reunião } \\
\text { presencial/Chat (Skype, limite de três participantes } \\
\text { em uma conferência). }\end{array}$ & $\begin{array}{l}\text { São, em sua maioria, alunos regularmente } \\
\text { matriculados em cursos de graduação e pós- } \\
\text { graduação da área da Saúde, do Campus UnB- } \\
\text { Ceilândia. }\end{array}$ \\
\hline $\begin{array}{l}\text { A síntese dos processos dialógicos estabelecidos } \\
\text { nesta reunião de pauta deve ser distribuída para } \\
\text { editoração como um alerta ou editorial. }\end{array}$ & $\begin{array}{l}\text { Um limite bem definido é estabelecido para a } \\
\text { utilização do fórum, sendo utilizada para integrar e } \\
\text { distribuir o produto da síntese dos processos } \\
\text { dialógicos estabelecidos na reunião de pauta aos } \\
\text { participantes extensionistas da UnB. }\end{array}$ \\
\hline $\begin{array}{l}\text { Os demais integrantes do Corpo Editorial da FMRP } \\
\text { podem emitir comentários e contribuições. } \\
\text { Os produtos da ação colaborativa são submetidos } \\
\text { à Edição Científica e Edição de desenvolvimento e } \\
\text { programação e disponibilizados mensalmente em } \\
\text { www.dol.inf.br }\end{array}$ & $\begin{array}{l}\text { Os demais integrantes do Corpo Editorial da FMRP } \\
\text { não podem emitir comentário e contribuições, à } \\
\text { exceção do editor científico. }\end{array}$ \\
\hline & http://www.dol.inf.br/asp/discussao/Nsforum.asp \\
\hline
\end{tabular}

Existem escolhas pedagógicas no direcionamento do fluxo de trabalho, dependentes do grau de escolaridade dos membros da equipe (Tabelas 4 e 5). Os participantes do projeto na USP têm autonomia em escolher as publicações que quiserem, atendendo somente o requisito de o tema ser relacionado com o estudo da Dor. Os participantes do projeto na UnB, sendo ainda graduandos, não possuem tal autonomia. Para estes, a escolha dos artigos se limita a uma única publicação mensal, a revista Pain, da International Association for Study of Pain. A seleção de artigos trabalhados é feita com base na edição mensal correspondente e, em média, três artigos são selecionados para serem apresentados e discutidos em reuniões presenciais, cabendo a produção colaborativa ser desenvolvida no fórum, a partir da síntese dialógica dos assuntos tratados na reunião presencial, em que o artigo é apresentado por um dos extensionistas, com auxílio de recursos audiovisuais. A intenção é expandir a experiência comunicativa para além do momento presencial, auxiliando o desenvolvimento crítico e exercitando o jornalismo científico, potencializado pelo emprego da gestão da Comunicação no AVA e uso de ferramentas apropriadas.

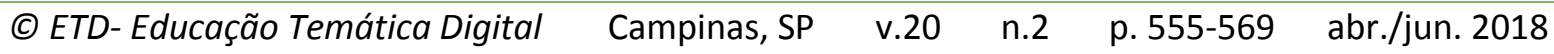


TABELA 4: Comparação da participação discente em cada Ambiente Virtual utilizado no Projeto de Extensão.

\section{Recurso 1}

Os participantes podem postar textos científicos da área do estudo da Dor e generalidades a esse respeito. Geralmente o abstract do trabalho é disponibilizado, com referências.

O trabalho é apresentado oralmente em reunião de pauta, para sua discussão e deliberação de aproveitamento, como um alerta de divulgação científica ou de Ciência \& Tecnologia (Modalidades de texto para audiências específicas).

A partir da discussão do artigo pelo corpo editorial, o mesmo aluno sintetiza e elabora um alerta ou editorial, como contribuição à elaboração da edição mensal do Boletim Dor Online.

Os demais participantes podem comentar as entradas do fórum, contribuindo com a discussão.

As disciplinas Revisão e Discussão da Literatura Experimental e Clínica Atual sobre Dor e Analgesia I e II são disciplinas de 60 horas semestrais, no programa de pós-graduação em Farmacologia da FMRP.

\section{Recurso 2}

Os participantes podem postar textos produzidos São artigos publicados no mês, da publicação internacional Pain, pertencente à International Association for the Study of Pain.

O trabalho é apresentado oralmente em reunião de pauta, para sua discussão e deliberação de aproveitamento, como um alerta de divulgação científica ou de Ciência \& Tecnologia (Modalidades de texto para audiências específicas).

A partir da discussão do artigo pelo corpo editorial, o mesmo aluno sintetiza e elabora um alerta ou editorial, como contribuição ao fórum dedicado à editoração da edição mensal.

Os demais participantes podem comentar as entradas do fórum, contribuindo com a discussão.

Existem bolsistas remunerados, com carga horária de 80 horas mensais, e extensionistas voluntários, com carga horária de 60 horas mensais. Podem ser transformadas em créditos de extensão no cômputo geral de carga horária obrigatória dos cursos de graduação envolvidos.

$\mathrm{Na}$ UnB, existe também o atendimento, por parte do projeto, à política institucional de utilização de AVAs para a melhoria do ensino de graduação e à prática de extensão universitária.

O produto resultante do projeto, sua edição mensal e demais conteúdos disponíveis no portal www.dol.inf.br, tem o objetivo de disseminação científica e crítica do estudo da Dor. A edição mensal é enviada para listas com mais de 2.500 endereços eletrônicos. Estes endereços são obtidos por solicitação direta do interessado em receber o boletim ou por pesquisa ativa em bases de dados de grandes hospitais, em outras IES com pesquisa na área da Dor, Institutos de Pesquisa, entre outros. A intenção é a divulgação dos avanços obtidos no estudo da Dor, em conjunto com a incorporação de aspectos críticos obtidos a partir da elaboração colaborativa das discussões e análises realizadas na elaboração da pauta, consonantes com linhas de pesquisa clínica e experimental praticadas pelos integrantes.

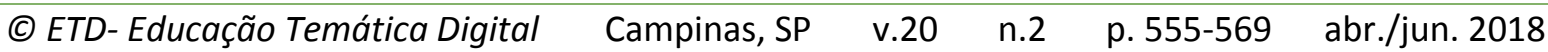


Tabela 5: Comparação da possibilidade de interação e interatividade entre os Ambientes Virtuais utilizados no Projeto de Extensão.

Recurso 1

Interação mútua e interatividade são exploradas durante as reuniões de pauta.

O fórum apresenta uma função para a interação reativa, a partir da ação anterior, baseada em interação mútua.

Atua na área de gestão da comunicação nos espaços educativos, possibilitando uma abordagem sistêmica da atividade de editoração de um recurso de comunicação de uma disciplina de um programa de pós-graduação em Farmacologia.

Promove um ecossistema comunicativo.

Está inserido em uma cadeia produtiva editorial, produzindo material de comunicação no estudo da Dor, para disseminação em nações de língua portuguesa.
Interação mútua e interatividade são exploradas durante as reuniões de pauta.

O fórum apresenta a função de estender o processo elaborativo por interação mútua, para além do ambiente da ação anterior.

Atua na área de gestão da comunicação nos espaços educativos, possibilitando uma abordagem sistêmica da atividade de editoração de um recurso de comunicação de um projeto de extensão universitária em Comunicação.

Promove um ecossistema comunicativo.

Está inserido em uma cadeia produtiva editorial, produzindo material de comunicação no estudo da Dor, para disseminação em nações de língua portuguesa.

Durante os 18 anos de projeto, um vasto banco de dados com alertas e editoriais permite a construção de uma visão histórica de uma década e meia do Estudo da Dor.

Diante do exposto, temos que o projeto Boletim Dor on line faz uso intensivo de recursos de ensino a distância, com o objetivo de disseminação cultural e científica, com ênfase em desenvolvimento tecnológico e farmacêutico. O projeto é constituído por uma equipe multidisciplinar para sua estruturação e funcionamento.

Quanto à avaliação de seu impacto sobre os alunos extensionistas, existe um dado obtido por questionário, respondido por 21 sujeitos com afiliação ao projeto de extensão, que demonstra o seu uso como uma base de dados de pesquisa para apoio a disciplinas de graduação, como Farmacologia e Toxicologia, além da possibilidade de atualização em áreas de pesquisa. A maioria dos entrevistados também afirmou que existe contribuição do Dol para sua formação acadêmica e acreditam que o ele é uma ferramenta que contribui eficazmente para a divulgação científica (Marra, 2016).

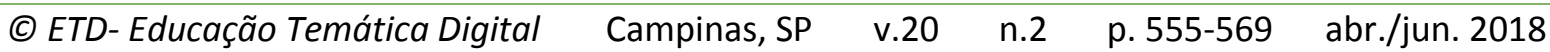




\section{DISCUSSÃO E PERSPECTIVAS EDUCOMUNICATIVAS}

O projeto pode ser considerado uma ação de educomunicação, por atuar especificamente na Educação para a Comunicação, com ênfase na formação de consciência crítica dos participantes do projeto e dos usuários recipientes do boletim mensal e do sítio www.dol.inf.br. O projeto se utiliza da mediação tecnológica nos espaços educativos, disponibilizando, inclusive, a seção de Divulgação Científica para a população leiga no estudo da Dor, contribuindo para a democratização e disseminação científica de terapias e avanços tecnológicos dessa área.

O projeto se utiliza da gestão da Comunicação nos espaços educativos, sobretudo no incentivo ao uso do Fórum do EVA da UnB por graduandos, visando à consolidação de um ecossistema comunicativo, de maneira a potencializar o desenvolvimento crítico no estudo da Dor e sua consequente disseminação ao público leigo e especializado.

Ferramentas do ensino a distância estão inseridas em uma cadeia produtiva editorial, produzindo media no estudo da Dor, para disseminação em nações de língua portuguesa.

Uma melhora consistente na avaliação crítica e postura em apresentar trabalhos científicos pode ser observada nos extensionistas pelos coordenadores do projeto. Isto melhora a qualidade dos textos comunicativos elaborados, contribuindo para uma melhoria de qualidade da edição mensal do projeto, propiciando aprendizado significativo aos participantes em um contexto de formação profissional. Esse aprendizado significativo é apoiado por ferramentas tecnológicas que dão suporte à produção de materiais e situações de aprendizagem internas e externas ao projeto.

\section{REFERÊNCIAS}

Aprender.unb.br. Acesso em: 03 de novembro, 2015, Disponível em:

http://aprender.unb.br/index.php/institucional

Bueno, W. C. Comunicação cientifica e divulgação científica: aproximações e rupturas conceituais. Informação \& Informação, v. 15, supl., p.1-12, 2010. Disponível em: http://doi.org/10.5433/1981-8920.2010v15nesp.p1

Farmácia (FCE/UnB), C. Projeto pedagógico do curso de farmácia. UnB. Brasília: UnB, 2010. Disponível em:

http://www.fce.unb.br/images/documentos/farmacia/projeto pedagogico do curso 1303 2014.pdf

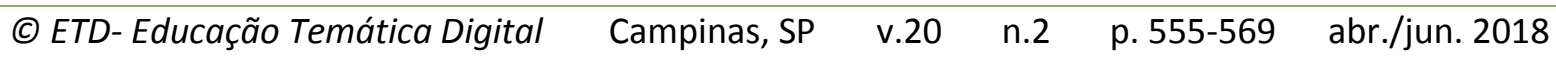


Hase, S., \& Kenyon, C. From andragogy to heutagogy. Acesso em: 06 de novembro, 2015. Disponível em http://www.psy.gla.ac.uk/ steve/pr/Heutagogy.html

Johnson, L.; Adams Becker, S., Estrada, V.; Freeman, A. (2015). NMC Horizon Report: 2015 Higher Education Edition. Disponível em: https://www.nmc.org/nmc-horizon/

Marra, T. M. G. A dor e o Dol - Dor on line como ferramenta de divulgação científica. 2016. 43 f., il. Trabalho de conclusão de curso (Bacharelado em Farmácia) - Universidade de Brasília, Ceilândia-DF, 2016. Disponível em: http://bdm.unb.br/handle/10483/13847

Moore, M. G. Theory of transactional distance. In D. Keegan (Ed.), Theoretical Principles of Distance Education. London; New York: Routledge, 1997. p. 22-38.

Soares, I. D. O. (2014). Educação Educomunicação e Educação Midiática : vertentes históricas de aproximação entre Comunicação e Educação. Comunicação \& Educação, São Paulo, v. 19, n. 2, p. 15-26, jul./dez. 2014.

\section{AGRADECIMENTOS ${ }^{i}$}

O projeto Boletim Dor on line agradece ao Decanato de Extensão da Universidade de Brasília pelo apoio financeiro e pelas bolsas de extensão do programa PIBEX que auxiliaram a implementação das atividades descritas neste trabalho.

\footnotetext{
${ }^{\text {i } R e v i s a ̃ o ~ g r a m a t i c a l ~ d o ~ t e x t o ~ s o b ~ a ~ r e s p o n s a b i l i d a d e ~ d e ~: ~ P r o f a . ~ V a l c l e i a ~ M a r q u e s ~ P e r e i r a ~ d e ~}$ Oliveira
} 